\title{
Die Beschränkung der Rückwirkung von Entscheidungen des Europäischen Gerichtshofs
}

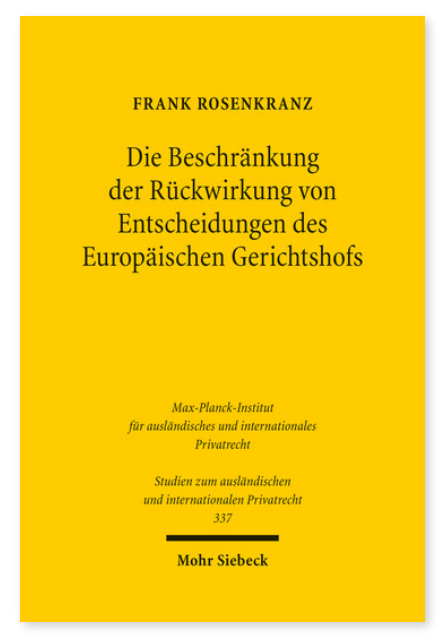

2015. XXXII, 584 Seiten. StudIPR 337

ISBN 978-3-16-153662-5

DOI 10.1628/978-3-16-153662-5

eBook PDF 114,00€

ISBN 978-3-16-153647-2

fadengeheftete Broschur 114,00€
Wenn der EuGH entscheidet, erweist sich nicht selten, dass das nationale Recht mit den unionsrechtlichen Vorgaben unvereinbar ist: Die Rechtslage ist anders als gedacht, und zwar rückwirkend. Die Folgen für EU, Mitgliedstaaten und andere Rechtsunterworfene können dann ganz erheblich sein und die Frage nach einer Beschränkung der zeitlichen Wirkung aufwerfen. Den zugrunde liegenden Konflikt der Geltung des Unionsrechts und der Rechtssicherheit erörtert Frank Rosenkranz von einem rechtstheoretischen Ausgangspunkt. Er analysiert die vom Gerichtshof aufgestellten Tatbestandsvoraussetzungen und Rechtsfolgenanordnungen unter Einbeziehung sämtlicher Rechtsgebiete und Verfahrensarten. Dies liefert neue Erkenntnisse über die im Detail ausdifferenzierte Rechtsprechung. Da das Unionsrecht im Mehrebenensystem nur eine von mehreren Komponenten der Rechtsanwendung darstellt, klärt der Autor abschließend, welche Auswirkungen die Rückwirkungsbeschränkung auf die mitgliedstaatlichen Rechtsordnungen hat und welche Spielräume für nationalen Vertrauensschutz verbleiben.

Frank Rosenkranz Geboren 1979; Studium der Rechtswissenschaften an der Europa-Universität Viadrina in Frankfurt (Oder); Wissenschaftlicher Mitarbeiter an der Ruhr-Universität Bochum; Referendariat am Oberlandesgericht Hamm mit Stationen in Bochum, Dortmund, Düsseldorf und Tel Aviv/Israel; 2009-14 Promotionsstudium an der Ruhr-Universität Bochum; 2011 Forschungsaufenthalt an der Harvard Law School; seit 2014 Akademischer Rat a.Z. an der Ruhr-Universität, Bochum.
Jetzt bestellen:

https://mohrsiebeck.com/buch/die-beschraenkung-der-rueckwirkung-von-entscheidungen-des-europaeischen-gerichtshofs9783161536625?no_cache=1

order@mohrsiebeck.com

Telefon: $+49(0) 7071-923-17$

Telefax: +49 (0)7071-51104 